\title{
AUTO CUIDADO NO TRATAMENTO PELO MÉTODO DE ILIZAROV - UM ESTUDO DE CASO
}

\author{
Marisa Toshiko Ono Tashiro' \\ Mariana Fernandes de Souza² \\ Sandra Denise de Oliveira ${ }^{3}$
}

\begin{abstract}
RESUMO: As autoras realizaram um estudo de caso com aplicação do modelo de auto cuidado de Dorothea Orem, no tratamento pelo método de llizarov, utilizando cuidados e orientações específicas para a recuperação e prevenção de complicações. A operacionalização do estudo constou de procedimentos relativos às demandas de cuidados universaise terapêuticos, durante a hospitalização. As demandas foram detectadas no préoperatório e os cuidados desenvolvidos no pós-operatório, facilitando ao paciente o aprendizado e a realização dos procedimentos necessários a dar continuidade dos mesmos no seu domicílio.
\end{abstract}

UNITERMOS: Auto cuidado-Educaçãodo paciente-Cuidados pós-operatórios-Ortopedia

\section{INTRODUÇÃO}

O homem brasileiro é carente de informações e orientações relativas ao seu estado de saúde, 0 que provoca alta reincidência de doenças e complicações associadas.

O ser humano necessita de motivação e interesse para desempenhar, e conduzirqualquer atividade ao objetivo pretendido. Segundo OREM(5), o homem é uma unidade funcionalmente biológica, simbólica e social. Ele vive em íntima relação com o meio ambiente, tentando adaptar suas necessidades de saúde ao estresse do meio, através de mecanismos para controlar esatisfazer suas necessidades.

A característica principal do homem é seu ativo e permanente metabolismo. Os processos metabólicos representam tanto um fluxo de matéria, como de energia, que entra e sai dó organismo num estado dinâmico de transformações. Estes mantêm a função constante através de ajustes e adaptações a seu ambiente interno e externo (2).

Quando existe um déficit no mecanismo fisiológico, as necessidades do indivíduo se alteram, levando-o a uma demanda de cuidados mais intensivos; os valores e normas sociais também podem sofrer modificações em decorrência do tratamento. Muitas vezeso paciente necessita de apoio e orientaçōes para manterseu equilíbrio diante de ações selecionadas para o tratamento.

A enfêrmagem existe para atender às necessidades das pessoas e é responsável para ajudá-las nas limitações e déficts no cuidado de si mesmas $^{(1)}$.

A tendência atual é a de enfatizar a saúde e sua promoção. A experiência mostra que a orientação para o auto cuidado é parte intrínseca do papel do enfermeiro. A cada dia percebe-se como desafio a necessidade do enfermeiro desenvolver e adaptar o seu conhecimento para atender às necessidades e expectativas da população quanto a cuidados preventivos, curativose de reabilitação.

\section{AUTO CUIDADO}

A enfermagem preocupa-se em selecionar

Enfermeira, docente da disciplina de Fundamentos de Enfermagem e Enfermagem· Médico-Cirúrgica, Departamento de Enfermagem da Escola Paulista de Medicina.

2 Enfermeira, Professora Titular da Disciplina de Fundamentos de Enfermagem e Enfermagem Médico-Cinúrgica, Departamento de Enfermagem da Escola Paulista de Medicina.

3 Aluna do $4^{\circ}$ ano de Graduaçáo em Enfermagem, Departamento de Enfermagem, Escola Paulista de Medicina. 
e promover atividades de auto cuidado, que são ensinadas e aprendidas pelo cliente de acordo com as crenças, valores, hábitos e práticas que caracterizam o seu modo de vida dentro de um

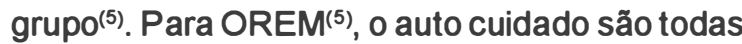
as práticas que o indivíduo inicia , executa para si próprio e para outros na manutenção da vida, saúde e beın-estar.

O enfermeiro orienta, intervém no cuidado do indivíduo com déficits, em três etapas: diagnóstico, elaboração e execução do plano de cuidados, que varia de acordo com asnecessidades do indivíduo, caracterizando os sistemas de enfermagem.

Nos sistemas de enfermagem, o enfermeiro atua como reguladordo auto cuidado, estabelece a forma e o relacionamento com o paciente. Ele identifica os déficits, executa aquilo que o paciente não consegue fazer, ensina, orienta e promove o desenvolvimentos de suas capacidades, tomandoo independente da assistência de enfermagem e, conseqüentemente, assumindo o auto cuidado.

OREM $^{(5)}$ classifica os sistemas de enfermagem em: totalmente compensatório - quando o paciente é incapaz de se auto cuidar, necessitando de cuidados integrais de enfermagem; parcialmente compensatório - sistema em que o paciente compartilha a responsabilidade do auto cuidado com o enfermeiro; sistema de suporte educativo - apoio, orientação e instrução.

Na prática de enfermagem, toma-se necessária uma avaliação diária, atualizada e contínua com o paciente , a fim de se adequar o plano de assistência às necessidades e habilidades individuais.

\section{O MÉTODO DE ILIZAROV}

O método de llizarov é uma técnica que vem sendo desenvolvida desde 1951, para tratamento de patologias osteoarticulares. ILIZAROV(3), na tentativa de manter a fixação óssea, desenvolveu um fixador circular, tornando possivel a combinação de métodos biomecânicos de estimulação da circulação de tecido ósseo neoformado. Esta técnica possibilitou preservar a circulação endostal e periostal, permitindo a compressão e distração do foco de pseudo-artrose.

Segundo VIDAL et al. ${ }^{(8)}$, vários autores desenvolveram tipos de fixadores, entre os quais podemos citar: fixador unilateral - apresenta uma barra rígida através de pinos, sendo esta a armação mais simples; b) fixador bilateral, que é composto por duas hastes rígidas em ambos os lados do membro afetado, pormeio de pinos que transfixam o osso; c) fixador triangular - tem três hastes rígidas onde os pinos são colocados em dois ou mais planos para aumentar a estabilidade; d) fixadorquadrilateral-é formado porquatro barras, duas de cada lado do membro afetado e os pinos são conectados entre si; e) fixador semi-circularé composto de hastesque circundam parcialmente o membro afetado; f) fixador circular ou externo de llizarov - é composto de hastes que envolvem completamente o membro afetado. Este fixador tem sido muito usado nas últimas décadas.

Apesar de vários estudos relacionados a fixadores externos, não existem indicações absolutas, cada caso deve ser individualizado pelo médico.

Este método apresenta vantagens e desvantagens em sua utilização. Algumas vantagens, segundo $S I S K^{(7)}$, são: movimentação pós-operatória imediata das articulações distaise proximais ao aparelho; facilita a redução de edema; aumenta a nutrição das superfícies articulares; retarda a fibrose capsular; diminui a rigidez articular e a osteoporose; ainda, permite supervisão direta do membro, a compressão, distração ou neutralização dos fragmentos da fratura e os tratamentos associados como troca de curativos, enxerto de pele, enxerto ósseo e irrigação, sendo possivel mantero alinhamento da fratura.

As desvantagens, segundo SISK ${ }^{(7)}$ ePALEY(6), são: as refraturas, após a remoção do aparelho; fratura durante a passagem do pino; infecção no trajeto dos pinos, se não houver uma técnica asséptica durante 0 procedimento cirúrgico e adequada manutenção do aparelho; rigidez articular, se a fratura requerer imobilização da articulação adjacente.

SISK ${ }^{(7)}$ relata que o uso comum desse tipo de tratamento tem acarretado uma série de complicações. $O$ autor defende que a utilização de uma técnica própria, seguindo princípios básicos de anatomia e microbiologia, pode manteras complicações num nivel mínimo. Ascomplicações mais comuns são: infecções no trajeto dos pinos, retardo de consolidação, síndrome compartimental e refratura.

Apesardas complicaçõesjá evidenciadas pelos autores citados, o método é utilizado com frequência no crescimento e amadurecimento ósseo, o que torna necessários cuidados especificos na manutenção do aparelho e do membro 
afetado. Este método, segundo MACHADO (4), desde que tecnicamente bem realizado e acompanhado por equipe multidisciplinar, permite alcançar resultados satisfatórios.

Diante disto, foi elaborada orientação baseada na teoria do auto cuidado de Dorothea OREM(5), para um paciente em tratamento pelo método de llizarov, utilizando cuidados específicos para a sua recuperação e prevenção de complicações.

\section{HISTÓRIA DO PACIENTE}

Paciente L.H.M.S., 21 anos, masculino, branco, natural de Belém do Pará, com história de trauma, resultando em fratura fechada transversa de fêmur E. Como tratamento, foi submetido a uma osteossíntese com haste intramedular, mais circlagem a foco aberto, que evoluiu para osteomielite, sendo necessária a retirada da haste, limpeza cirúrgica e colocação de colar de Gentamicina. Como não apresentou efeito satisfatório, o mesmo foi retirado e o paciente encaminhado para o serviço da Escola Paulista de Medicina.

O paciente chegou com tração esquelética em 1/3 proximal de tíbia E, e após avaliação médica, optou-se pelo tratamento com fixador esterno de llizarov. No quinto dia de internação foi realizado o procedimento cirúrgico no fêmur esquerdo.

\section{Método}

Este estudo foi operacionalizado através de procedimentos relativos às demandas de cuidados universais e terapêuticos durante a hospitalização do paciente. Os déficits de auto cuidado forma detectados no pré-operatório, e os cuidados desenvolvidos no pós-operatório, o que permitiu o aprendizado e a realização dos procedimentos pelo paciente e por um membro da família.

Durante a prestação da assistência houve a participação do pai na execução das atividades de autocuidado terapêuticas e universais. Este acreditou ser fundamental receber as orientações, pois desconhecia cuidados a serem dispensados ao filho. A sua participação :ontribuiu para continuidade dos cuidados nas vinte e quatro horas do dia, principalmente com relação aos exercícios e as atividades de vida diária, durante a hospitalização, como por exemplo, a higienização, exercícios com o membro afetado e a manutenção do aparelho.

A avaliação foi realizada diariamente no que se refere às demandas de auto cuidado terapêutico, como: exercício do membro afetado, curativo da ferida cirúrgica, limpeza das inserções dos pinos e do aparelho, estimulação do transporte ósseo, e às demandas de auto cuidado universais.

A partir da identificação dos déficits de auto cuidado, elaborou-se um plano de assistência pelo sistema de enfermagem parcialmente compensatório esuporte educativo conforme abaixo.

\section{QUADROI- PROCEDIMENTOS ESPECÍFICOS DE ENFERMAGEM NO TRATAMENTO PELO}

MÉTODODEILIZAROV

\begin{tabular}{|l|c|c|}
\hline \multicolumn{1}{|c|}{ PROCEDIMENTO } & $\begin{array}{c}\text { NÜMERO } \\
\text { DE VEZES }\end{array}$ & DIA \\
\hline DE P.O.
\end{tabular}


Este sistema foi aplicado e avaliado durante os trinta dias de internação, sendo que o paciente foi assumindo gradativamente as atividades de auto cuidado. Nos cinco primeiros dias de intemação, o pacienteencontrava-secomtração esquelética; nestafase, foraminiciadas as primeiras orientações. Noquintodia o paciente foi submetido ao procedimento cirúrgico: colocaçãod ofixador extemo de llizarov, novigésimo primeirodia foifeitaa corticotomia, enotrigésimo dia de internação teve alta hospitalar. Esta alta correspondeu aovigésimo quinto diade pós-operatório de colocação do fixador extemo de llizarove oitavo dia decorticotomia.

\section{RESULTADOS E DISCUSSÃO}

Com relação à flexão do pé, extensão plantar, exercício isométrico do quadríceps, exercício isométrico de glúteo e extensão do. membro afetado, ao se aplicar a contra-tração, observouse que a partir do quarto dia de pós-operatório, 0 paciente realizava estas atividades de acordo coma orientação recebida. Para estas atividades, constatou-se que o paciente se auto cuidava parcialmente desde o primeiro dia de pósoperatório, tornando-se independente a partir do quarto dia de cirurgia. Este fato demonstrou que a prática de auto cuidado ocorreu para a execução do plano elaborado pela enfermagem.

Com relação aos exercícios de abdução, adução e elevação do membro afetado, o paciente realizava parcialmente as orientações recebidas. Somente a partirdo sétimo dia de cirurgia, conseguiu elevar o membro com dificuldade, pois a força muscular estava diminuída. Durante a avaliação, detectouse a diminuição da capacidade da força muscular. Iniciou-se a aplicação de técnicas específicas, tipo massagens e Do-In, que foram meios para ajudar na recuperação destes déficits, passando o mesmo a realizá-los quinze vezes ao dia.

O exercício de flexão de joelho foi efetuado a partir do sétimo dia de pós-operatório, com dificuldade devido à dor, inicialmente, a uma flexão de 5 graus, que evoluiu gradativamente até a alta para uma flexão de $\mathbf{3 0}$ graus.

Com relação ao curativo e limpeza nas inserções dos pinos, observou-se o interesse do paciente, a partir do terceiro dia de pós-operatório. 0 paciente demonstrou dificuldade para realização deste, apenas no primeiro dia. OREM ${ }^{(5)}$ refere que o individuo tem potencial para desenvolver habilidades práticase intelectuaise manteruma motivação para o auto cuidado. A partir do momento que o páciente passou a realizar sua higiene corporal no chuveiro, os fiose arosdo aparelho eramlavadoscom água esabầo, e em seguida secos. Esta conduta facilitou o curativo nas inserções dos pinos. Apenas o curativo da incisão cinúrgica era realizado pela € quipe de enfermageme/ou médica, devidoà presença de infecção e a incisão estartotalmente aberta.

Verificou-se queapesardas orientaçõese avaliaçõesdiárias, algumas intercorênciasaconteceramno quetangeaorelaxamentoda musculatura, ocasionandoumaangulaçãodamesmanaregião correspondente à corticotomia. Fez-senecessánia umacontensãomais firme no local do abaulamentomuscular.

Novigésimo segundodiade intemaçãofoirealizada nova corticotomia. No segundo dia de pós-operatório desta, iniciou-se otransporte ósseo de $1 \mathrm{~mm}$ ao dia, ou seja, 1/4de volta a cada 6 horas. O paciente foi orientado com relação à importância deste procedimentoetambémquantoaos parafusosquedeveriam sertrabalhados. Nesta fase era notável a grande motivaçãodo paciente. Segundo OREM(5), a formade acão autocontroladae intemamente orientada podeser reconhecida como razões, para as ações e a busca de resultado.

Durante a sua evolução, observou-sepelosachadosradiológicos, que a qualidade de osso regenerado não era satisfatória, sendo necessária a redução da velocidadedotransporteósseo para $0,5 \mathrm{~mm}$ ao dia, ou seja, $1 / 4$ de volta a cada 12 horas.

No trigésimo dia de intemação, o paciente teve alta hospitalar. Nesse dia, foram enfatizadas todas as orientações para que o paciente desse continuidade ao tratamento e praticasse 0 auto cuidado em seu próprio domicílio. Percebeu-se o seu engajamento no auto cuidado, a valorização das práticasdo mesmo em relação à manutenção do aparelho e tratamento, objetivando a sua eficácia.

O paciente relatou que a participação da enfermeira no seu tratamento foi de suma importância na sua recuperação, pois além da eficiência dos cuidados recebidos, teve oportunidade de colocar suas dificuldades, angústias e dúvidas com relação ao tratamento. Relatou ainda, que os mecanismos utilizados pela enfermagem permitiramIhe independência e responsabilidade no cuidado de si próprio, valorizando sua pessoa e suas habilidades próprias.

Pelaavaliaçãodiária pode-se inferirqueo paciente se encontrava satisfeito e adaptado ao sistema de enfermagem, incorporandoasaçõespara oautocuida 
doe realizando comsegurança os procedimentos.

\section{CONCLUSÃO}

Este estudo de caso mostrou que uma orientaçãosistematizadaparao autocuidadotomouo pacienteindependente a partirdo sétimodiade pós- operatório, desenvolveu habilidadesparaocurativo, transporteósseo, higienecorporal, exercícios ativose isométricosdo membroafetadoe adeambulaçåo.

Ainda, pode-se concluirque a implementaçãodo autocuidado sefeznecessária para a manutençãodo aparelhoetratamento, umavezqueesteédemoradoe requera continuidade doscuidadosespecíficos.

\begin{abstract}
The authors performed a case study using Dorothea Orem's self-care model as a frameworkin thetreatment by llizarov's method, administering careand specificorientationsfor recovery and prevention of furtherdisorders. The operational system of the study consisted of proceduresrelated to demands of universal andtherapeuticcare during hospitalization. Demands were detected in the pre-operativeand care developed in the postoperative phase, providing the patientewith theknowledge and achivement of thenecessary procedures to be followed at home.
\end{abstract}

\title{
KEWWORDS: Self-care-Patient education-Posoperative care-Orthopedics
}

\section{REFERÊNCIASBIBLIOGRÁFICAS}

1- BRUNNER, L.S. \& SUDDARTH, D.S. Funçáo músculo esquelética. In: Tratado de enfermagem médico-cirürgica, RJ: Guanabara/Koogan, 1994. v.4, p.1513-1607.

2- DOUGLAS, C.R. Princípios de cibernética aplicada a fisiologia. In: Tratado de fisiologia aplicada às ciéncias da saúde. S.P: Robe Editorial, p.51-89, 1994.

3- ILIZAROV, G.A. The tension-stress effect on the genesis and growth of tissues. Part I - The influence of stability of fixation and soft-tissue preservation. Clin. Orthop. n.238, p.49-60, oct. 1989.

4MACHADO, I.R., NETO, J.L.P.S., RIBEIRO,M.C., CORDEIRO, H.C. Proposta de um protocolo para prevençáo e tratamento das complicaçóes no uso da técnica de ilizarov. Rev. Bras. Ort., v.27, n.8, p. 601-5, agosto, 1992.
5- OREM, D.E. Nursing-concepts of pratice. 4 ed. St.Louis: Mosby-Year Book, 1991.

6- PALEY, D. Problems, obstacles and complications of limb lengthening by the Ilizarov tecnique. Clin. Orthop. n.250, p.81-89, jan., 1990

7- SISK, T.D. External fixacion: histori review, advantages, disadvantajes, complications and indications. Clin. Orthop. n.180, p.15-21, nov., 1983.

8-VIDAL, J., BUSCAYRET, C. CONNES, H., MELKA, J., ORST, G. Guidelines for treatment of open fractures and infected pseudoarthroses by external fixation. Clin. Orthop. n.180, p. 83-95, nov., 1983.

Encaminhado para publicaçăo em 10/12/94

Aprovado para publicaçăo em 10/2/95. 